\title{
Structural Recovery of Face Value at Default
}

\author{
Rajiv Guha and Alessandro Sbuelz* \\ First Version: December 2002 \\ This Version: December 2005
}

\begin{abstract}
A Recovery of Face Value at Default (RFV) means receiving the same fractional recovery of par at default for bonds of the same issuer and seniority, regardless of remaining maturity. We find that RFV in a parsimonious structural credit risk model has a profound impact on hedging interest rate risk as it strongly affects model sensitivities to interest rates. In particular, RFV explains and quantifies two important stylized facts: i) the low empirical duration of high-yield bonds and ii) the decreasing sensitivity of credit spreads to interest rates as credit quality declines. The recovery form used in empirical studies influences their interpretation as the default-free term structure (level and slope) interacts with the recovery form in determining model credit spreads.
\end{abstract}

JEL-Classification: G12, G13, G33.

Keywords: Recovery Forms, Structural Credit Risk Models, Duration.

${ }^{*}$ Rajiv Guha is affiliated with CPIM, London, UK. Alessandro Sbuelz (corresponding author) is affiliated with the Department of Finance, University of Verona, Via Giardino Giusti 2, 37129, Italy, alessandro.sbuelz@univr.it, phone nr. +39-045-8054922. The former author worked on this research while he was not affiliated with CPIM. A previous version of this paper was entitled "Structural RFV: Recovery Form and Defaultable Debt Analysis". We thank seminar participants at BCI-Intesa Milan, Bologna University, INSEAD, Tilburg University, Vrije Universiteit in Amsterdam, the 2003 EFA Meetings in Glasgow, the evening CEPR-ESSFM-2004 sessions in Gerzensee, and the 2004 GRETA Conference Validation of Credit Risk Models in Venice for useful comments and suggestions. The usual disclaimer applies. CPIM does not have any responsibility for the contents and the results of this research. 


\title{
Structural Recovery of Face Value at Default
}

\begin{abstract}
A Recovery of Face Value at Default (RFV) means receiving the same fractional recovery of par at default for bonds of the same issuer and seniority, regardless of remaining maturity. We find that RFV in a parsimonious structural credit risk model has a profound impact on hedging interest rate risk as it strongly affects model sensitivities to interest rates. In particular, RFV explains and quantifies two important stylized facts: i) the low empirical duration of high-yield bonds and ii) the decreasing sensitivity of credit spreads to interest rates as credit quality declines. The recovery form used in empirical studies influences their interpretation as the default-free term structure (level and slope) interacts with the recovery form in determining model credit spreads.
\end{abstract}

JEL-Classification: G12, G13, G33.

Keywords: Recovery Forms, Structural Credit Risk Models, Duration. 


\section{Introduction}

Structural models of credit risk use option pricing theory to provide a fundamental framework for valuing the default risk inherent in corporate debt and related derivatives. A typical element of such models is the recovery form which specifies the way of valuing payments to bondholders when default occurs. One form, Recovery of Face Value at Default (RFV) means receiving the same fractional recovery of par at default for bonds of the same issuer and seniority, regardless of remaining maturity. RFV is a direct consequence of the debt acceleration clause in typical bond indentures. The claim acceleration clause implies that, at default, the principal amount and the accrued interest of the bonds outstanding is immediately payable ${ }^{1}$. RFV is also in line with US bankruptcy law. The stage of the Chapter 11 process that most directly affects the relative recovery values of bonds within the same class is the classification of claims as proposed in the reorganization plan. Only substantially similar claims can be put into the same class, so that same-seniority claims are very likely to be grouped in the same class. Yet within the same class no specific provisions are made for dealing with the bond-specific contractual details such as the maturity or coupon. Credit derivatives market participants generally assume RFV for pricing derivative contracts or for implementing capital structure arbitrage trades using proprietary models.

A case-study example of RFV is found in Table I and Figure 1 for Worldcom Incorporated ${ }^{2}$. We see that in the period leading up to the initial default event same seniority bond prices converge to similar values. In particular, short-dated bonds suffer comparatively more than longer maturity bonds. When Worldcom reveals the initial bad news of accounting irregularities on 26 June 2002 the price quote of the shortest dated bond, maturing on 15 May 2003, declines in value from 68.5 to 14 per 100 face value; at the same time the price of the bond maturing on 15 May 2031 goes from 38 to 11.25. When Worldcom eventually files for Chapter 11 bankruptcy protection on 21 July 2002, both bonds are quoted at 13.25 .

RFV is consistent with bond indenture language, US bankruptcy law, and defaulted bond values, and yet it is notable that RFV is not the typical recovery form assumption in the research of structural models of credit risk ${ }^{3}$. In recent years, the appeal of structural models has been

\footnotetext{
${ }^{1}$ The accrued interest is also immediately payable but it is dwarfed by comparison with the principal amount.

${ }^{2}$ Guha (2002) describes the data used in this example.

${ }^{3}$ Starting with the seminal Merton (1974) model, Eom, Helwege, and Huang (2004) empirically test a wide range of such models, none which are consistent with RFV. Likewise, Huang and Huang (2003) do not consider RFV in finding that credit spread underestimation is a robust characteristic across many structural credit risk models. Ericsson and Reneby (2002) use RFV to price individual bonds without providing any justification. Since their focus is on evaluating their model's ability to predict yield spread levels and changes out-of-sample, the recovery form used and its implications for bond price sensitivities are not discussed.
} 
revived by their ability of establishing a direct link between credit risk and capital structure, thus enabling important applications like equity-based credit risk management. We explore the consequences of incorporating RFV into a parsimonious structural credit risk model for the pricing and hedging of individual corporate bonds. Following the subset of models derived from Black and Cox (1976), model parsimony leads us to consider default as defined by the first time that a firm's asset value hits some exogenous boundary ${ }^{4}$. We find that RFV can help explain and quantify important stylized facts about the relationship between credit risk and default-free interest rates which other typical recovery forms cannot. RFV provides a simple explanation for both i) the low empirical duration of high-yield bonds and ii) the decreasing sensitivity of corporate credit spreads to interest rates as issuer credit quality declines. We also show that the recovery form interacts with the default-free term structure (level and slope) in determining model credit spreads. Since the level and slope of the default-free term structure changes through time, the employed recovery form affects the empirical validation of the model by influencing the model prediction errors.

It has been documented (e.g., Cornell and Green (1991)) that high-yield corporate bond prices have much lower sensitivity to default-free rates (i.e. modified duration) than what their promised cash flows imply. RFV explains that phenomenon with the fact that the bond investor receives a recovery claim at the time of default whose value is independent from default-free rates. Since participants in the high-yield market widely acknowledge that default-free rate sensitivities of high-yield bonds is not what their promised cash flows imply, RFV can be used in applications for hedging the interest rate risk embedded in individual credit-sensitive instruments and portfolios of such securities. We show how RFV contributes to a more informed investment management process by producing a clean measurement of the portion of promised-cashflows duration of an individual high-yield bond.

Duration and credit spread sensitivity to default-free interest rates are related. If duration is low, then credit spread sensitivity must be quite negative. This fact is a straightforward but powerful implication of the chain rule in calculating the derivative of the defaultable bond price with respect to the default-free rate. By implying a low duration of high-yield bonds, RFV also explains the decreasing sensitivity of corporate credit spreads to default-free interest rates as issuer

\footnotetext{
${ }^{4}$ Endogenous-boundary models also stem from Black and Cox (1976) (see for example Leland (1994), Leland and Toft (1996), and Acharya and Carpenter (2002)) but they are problematic for the study of the implications of the recovery form assumption. In these models, the recovery amount for the single bondholders is not specified as it is not the object of interest (Ericsson and Reneby (2002) are an exception). Due to the firm deciding default, the total amount recovered by the sum of all debtholders is not a primitive. It is difficult to distinguish the acts of the firm's choice of default time from the acts of the recovery form assumption. Davydenko (2005) empirically examines the default boundary using a sample of US firms.
} 
credit quality declines. There is robust empirical evidence that the regression coefficient of the credit spread changes on the default-free rate changes becomes more negative as credit quality decreases (see for example Duffee (1998) and Collin-Dufresne, Goldstein, and Martin (2001)). RFV's explanation is compellingly simple: the promised yield of low-credit-quality bonds is not affected much by default-free yield changes because bond pricing is dominated by considerations on the fixed payment at default. For low-credit-quality bonds, an increase in the default-free yield is nearly offset by a strong decrease of the credit spread, leading to a moderate change in the promised yield (the sum of the default-free yield and of the credit spread) generated within a RFV model. Given the increase in the default-free yield, the strength of the RFV credit spread decrease is enhanced by a constant value of the RFV payment at default.

Previous research never compared recovery forms within structural credit risk models although we see different embedded assumptions in the literature. The typical recovery form seen in exogenous-boundary structural credit risk models (for example, in Longstaff and Schwartz (1995), Cathcart and El-Jahal (1998), Hsu, Saa-Requejo, and Santa-Clara (2002)) is Recovery of Treasury (RT). RT states that, at the time of default, bondholders retrieve a given fraction of the default-free equivalent of the defaultable bond considered ${ }^{5}$. The RT payment at default is by construction dependent on default-free yields. We are the first to highlight that RFV and RT have a strong impact on the default-free interest rate hedging of low-credit-quality bond portfolios. For low-credit-quality bonds, an increase in the default-free yield is only in part offset by a decrease of the credit spread, leading to a significant change in the promised yield generated within a RT model. Given the increase in the default-free yield, the strength of the RT credit spread decrease is diminished by a dropping present value of the RT payment at default.

There is interaction between the default-free term structure (level and slope) and the recovery form in determining model credit spreads. If the curve is at the rate level that makes the defaultfree equivalent bond trade at par, RFV and RT credit spreads are equal. If the curve is upward (downward) sloping, RFV credit spreads are lower (higher) than RT credit spreads as the RFV payment at default is worth more (less) than the RT payment. Since the observed default-free term structure level and slope changes through time, the dynamics of the difference between the observed promised yields and the model-based yields is different across recovery forms. We are the first to point that the difference in the prediction error dynamics across recovery forms is an important concern in the empirical validation of structural credit risk models.

In the existent literature the comparative effect of the different recovery forms on credit risk

\footnotetext{
${ }^{5}$ Collin-Dufresne and Goldstein (2001) describe an exogenous-boundary structural model in which bondholders receive a fixed fraction of just the face amount at the maturity of the defaultable bond.
} 
pricing has only been examined in the context of intensity-based models. Duffie and Singleton (1999), Lando (2004), and Schoenbucher (2003) consider the theoretical pricing effects of RFV within an intensity-based model. In a detailed empirical study Bakshi, Madan, and Zhang (2002) compare different recovery forms (with RFV among them) within an intensity-based model using individual corporate bond price data. Delianedis and Lagnado (2002) and Finkelstein (1999) compare the effect of recovery form on credit default swap pricing and find that it does matter, but neither examines this issue within the context of a structural model.

The remainder of the paper proceeds as follows. Section 2 describes RFV and RT within the basic structural model setup. Section 3 studies interest rate durations generated within RFV and RT. Section 4 uses the duration results to assess the credit spread sensitivity to the default-free yield across recovery forms. Section 5 focuses on the interaction between the default-free term structure and the recovery forms. Section 6 concludes and the Appendix gathers the technical details.

\section{Structural Default Risk and Recovery Forms}

We consider the simplest of structural models which can reasonably be applied to coupon-paying bonds $^{6}$, a first-passage time model of a firm value process with constant interest rates and a constant default boundary. This simple and parsimonious model is considered the "base case" model in Huang and Huang (2003). Several reasons are behind our model choice.

Firstly, Huang and Huang (2003) show that, within the class of structural models, the base case explains the credit risk component of credit spreads as well as more sophisticated versions of it. This is suggestive that our results for studying comparative recovery forms under the base case may hold under more complicated settings. Secondly, the parsimonious base case allows us to fully concentrate on the comparative effects of the different recovery forms. Lastly, the base case leads to tractable closed-form solutions which greatly eases our analysis.

The underlying stochastic variable for default risk is the firm asset value process whose dynamics under the risk-neutral measure is modelled as follows:

$$
d V_{t}=(r-\delta) V_{t} d t+\sigma_{V} V_{t} d z_{V}^{Q}
$$

where $r$ is the constant default-free interest rate, $\delta$ is the assumed constant firm payout rate, and $\sigma_{V}$ is the assumed constant volatility of firm's asset value, and $z_{V}^{Q}$ is a standard Brownian motion

\footnotetext{
${ }^{6}$ For this reason we avoid the Merton(1974) model, which can be cumbersome to apply to coupon-paying bonds.
} 
under the risk-neutral probability measure. Default occurs at the first-passage time $\tau$ of $V$ hitting the constant default boundary, $K$ :

$$
\tau \equiv \inf \left(u>0, x_{u} \equiv \ln \left(\frac{V_{u}}{K}\right)=0\right)
$$

Such a boundary is usually economically justified by the presence of positive net worth or safety covenants (Black and Cox (1976)). Defining $x_{t}$ as $\ln \frac{V_{t}}{K}$, the log of the inverse leverage ratio $^{7}$, with positive initial value $x_{0}$, the risk-neutral cumulative default probability is:

$$
Q_{t}(\tau<T)=N\left(\frac{-x_{0}-\mu_{*}(T-t)}{\sigma_{V} \sqrt{T-t}}\right)+e^{-\frac{2 \mu_{*} x_{0}}{\sigma_{v}^{2}}} N\left(\frac{-x_{0}+\mu_{*}(T-t)}{\sigma_{V} \sqrt{T-t}}\right)
$$

where $N(\cdot)$ is the standard normal cumulative distribution function and $\mu_{*}$ is the risk-neutral drift for $x_{t}: \mu_{*} \equiv r-\delta-\frac{\sigma_{V}^{2}}{2}$.

Expressions for defaultable bond prices are straightforward in this simple setting. Our objective is to compare the implications of the different recovery assumptions. We partition the value of a defaultable bond with a face value of $F$ maturing at time $T$ paying semi-annual coupons ${ }^{8}$ at an annual rate of $c$ into two components: 1) valuation of payments in the states where no default occurs, and 2) valuation of payments in states where default occurs,

$$
P_{0, c, T}=P_{0, c, T}^{N D}+P_{0, c, T}^{D}
$$

The latter portion will vary with the recovery form we choose while the former part is independent of the recovery value. In other words, the first expression is equal to the value of the bond assuming a zero recovery value:

$$
P_{0, c, T}^{N D}=D(0, T) F\left[1-Q_{0}(\tau<T)\right]+\frac{c}{2} \sum_{i=1}^{2 T} D\left(0, T_{i / 2}\right)\left[1-Q_{0}\left(\tau<T_{i / 2}\right)\right]
$$

where $D\left(0, T_{i / 2}\right)$ is the value of the default-free discount bond maturing at $T_{i / 2}$, or in this setting: $\exp \left(-r T_{i / 2}\right)$. The partitioned value for the default states will depend on the recovery form. In all cases a constant recovery rate of $\omega$ is assumed.

We first present the typical form seen in the literature: RT (see for example Longstaff and Schwartz (1995)) .

\footnotetext{
${ }^{7}$ This interpretation is correct if we assume the level of the default boundary to proxy for the value of total liabilities of the firm.

${ }^{8}$ Discount bond prices arise by setting the coupon rate to zero.
} 


\section{Recovery of Treasury (RT):}

$$
P_{0, c, T}^{D, R T}=\omega\left[D(0, T) F Q_{0}(\tau<T)+\frac{c}{2} \sum_{i=1}^{2 T} D\left(0, T_{i / 2}\right) Q_{0}\left(\tau<T_{i / 2}\right)\right] .
$$

At default, RT bondholders receive the value of a default-free bond with the same contractual features of the defaultable bond.

We now consider the RFV case where the debtholder receives a fraction of the face value of the bond at the default date ${ }^{9}$.

\section{Recovery of Face Value at Default (RFV):}

$$
P_{0, c, T}^{D, R F V}=E_{0}^{Q}\left[\mathbf{1}_{\{\tau<T\}} \exp (-r \tau) \omega F\right]
$$

We can write this expression as $\omega F$ multiplied by today's value of a unit payment received at default. This latter term describes the price of an American digital option (see for example Nelken (1996)):

$$
\begin{gathered}
E_{0}^{Q}\left[\mathbf{1}_{\{\tau<T\}} \exp (-r \tau)\right]=\left[e^{\frac{-x_{0}\left(\mu_{*}+\lambda\right)}{\sigma_{v}^{2}}} N\left(\frac{-x_{0}+\lambda T}{\sigma_{V} \sqrt{T}}\right)+e^{\frac{-x_{0}\left(\mu_{*}-\lambda\right)}{\sigma_{v}^{2}}} N\left(\frac{-x_{0}-\lambda T}{\sigma_{V} \sqrt{T}}\right)\right] \\
\text { where } \lambda \equiv \sqrt{\mu_{*}^{2}+2 \sigma_{V}^{2} r}
\end{gathered}
$$

We make use of American digitals as a modelling vehicle for a recovery form ${ }^{10}$ supported by defaulted bond price data, bond indentures, and bankruptcy code language.

For choosing the parameters which do not vary across credit quality we refer to Huang and Huang (2003). These include the constant interest rate $r(8.00 \%)$, the constant payout rate $\delta(6.00 \%)$, the default boundary $K$, assumed to be $60 \%$ of the firm's total liabilities; and an expected recovery rate $\omega$ of $51.31 \%$. For the parameters which would likely vary across credit quality

\footnotetext{
${ }^{9}$ In the more general form of RFV any accrued interest on the last coupon payment prior to default should be included in the recovery payment if stipulated as such in the bond indenture. We ignore this feature in our analysis.

${ }^{10}$ American digitals have been applied before for corporate bond pricing by Black and Cox (1976), Leland and Toft (1996), and Ericsson and Reneby (2002). They study the value-maximizing decisions of the firm manager. It is difficult to distinguish the acts of the maximizing assumption from the acts of the recovery form assumption.
} 
we use mean estimates from Davydenko and Strebulaev $(2002)^{11}$. These include the leverage ratio, as measured by the book value of total liabilities divided by the sum of the book value of total liabilities and the market value of equity, and the asset value volatility. Table II shows their estimates across the credit rating classes. While the results in absolute terms will depend highly on our choice of parameters, we are concerned with the relative difference in spreads across the recovery forms. The choice of assuming a constant recovery rate $\omega$ across the recovery forms is deliberate given the purpose of investigating the relative difference in spreads. In applications, the parameter $\omega$ is typically an exogenous input based on historical data.

\section{$3 \quad$ Duration and Recovery Forms}

Portfolio managers with investment-grade benchmarks are often allowed out-of-benchmark allocations to high-yield debt. Thus, understanding the effect such allocations have on the overall portfolio duration is important.

It is widely acknowledged that the default-free rate sensitivity of high-yield securities is not necessarily what their promised cash flows imply ${ }^{12}$. Indeed, it is well known empirically that the duration of a bond tends to decline as default becomes imminent. For example, Cornell and Green (1991) show that the empirical duration (i.e., the return realized per unit of yield change) of low-grade bonds is lower than that for high-grade bonds and suggest that this may be partly due to the fact that coupons are higher for low-grade bonds ${ }^{13}$.

We show that the recovery form assumed in a parsimonious structural credit risk model deeply affects the model sensitivities to default-free rates. Our results quantify the intuition that, due to differences in default-free-rate dependence of the cash flow payments across the recovery forms, different default-free rate sensitivities are produced by each recovery form. We consider two model

\footnotetext{
${ }^{11}$ In Huang and Huang(2003) the asset volatility parameter is calibrated to match the data, and thus vary for different maturities. While we could use their data on leverage ratios for the different credit rating classes, we decide to take these two parameters from a consistent source.

${ }^{12}$ Many claim that high-yield debt exhibits rather equity-like behavior (see for example Campi and Sbuelz (2005), Campi, Polbennikov, and Sbuelz (2005), and Vassalou and Xing (2004).

${ }^{13}$ Dynkin, Hyman, and Konstantinovsky (2004) confirm this finding with recent daily data over the period: August 1998- September 2004. They regress daily price returns of whole-letter-grade components of the Lehman InvestmentGrade and High-Yield Credit indices against daily changes in the 10-year U.S. Treasury yield. The (negative of the) regression coefficients can be interpreted as empirical durations. These are compared to the classical modified durations (as defined in this section, that is, as the negative semi-elasticity of the model bond price with respect to its promised yield) for each index over the same period. In higher quality bonds, the empirical durations are almost identical to classical modified durations; for lower quality bonds, the empirical durations become much smaller than the classical modified durations.
} 
sensitivity measures: 1) the derivative of the model bond price with respect to the default-free rate: $\frac{\partial P_{0, c, T}^{j}}{\partial r}$, and 2) the negative semi-elasticity of the model bond price with respect to the default-free interest rate, or the model modified duration:

$$
D u r_{0, c, T}^{j} \equiv-\frac{1}{P_{0, c, T}^{j}} \frac{\partial P_{0, c, T}^{j}}{\partial r}
$$

for $j=\{R T, R F V\}$. The classical modified duration is the negative semi-elasticity of the model bond price with respect to its promised yield. Given the following notation,

$$
\begin{aligned}
p_{W} & =\text { price of corporate bond } W, \\
y_{W} & =\text { promised yield of bond } W, \\
y & =\text { default-free equivalent bond yield, } \\
s_{W} & =y_{W}-y \quad \text { (credit spread) },
\end{aligned}
$$

where $y$ equals $r$ in a flat term structure of default-free rates, modified duration and classical modified duration are related by this simple but important equation:

$$
\frac{1}{p_{W}} \frac{d p_{W}}{d y}=\frac{1}{p_{W}} \frac{d p_{W}}{d y_{W}} \cdot\left(1+\frac{d s_{W}}{d y}\right),
$$

that is,

$$
\begin{aligned}
\text { modified duration }_{W}= & \text { classical modified duration } \\
& \cdot(1+\text { spread sensitivity to rates }) .
\end{aligned}
$$

For investment-grade credit quality the sensitivities are essentially the same across all recovery forms due to default being an unlikely event. However, as the credit quality decreases the sensitivity as implied by the two recovery forms diverge. When default is close, bondholders expect to receive imminently the recovery payment specified by the recovery form. Bondholders receive a fixed 
payoff at default under RFV, whereas they receive a default-free-rate-dependent payoff (a fraction of the default-free equivalent bond price) under RT. As asset volatility and leverage increase, the modified duration of an RFV bond decreases substantially more than RT. Hence, structural RFV is able to match the stylized fact that empirical durations for low-grade bonds are quite low. The explanation is simple: RFV specifies a default-free-rate-insensitive payoff at default. Our parsimonious structural model quantifies how much weaker the default-free-rate sensitivity of lowgrade bond prices is under RFV than under RT. Figure 2 plots the derivative against maturity for a hypothetical speculative-grade (B-rated) bond. The coupon rate is chosen to be equal to the default-free rate $(8.00 \%)$. The same plot in terms of the model modified duration is shown in Figure 3. The RT form has a significantly more negative sensitivity to default-free rates and a considerably higher modified duration. For example, in the 30-year maturity case the RT modified duration is 8.69 while the RFV modified duration is 5.32. An important point here is that the coupon in these figures is equal to the default-free rate so that RFV and RT corporate bond model prices are the same. If $c \simeq 8 \%$, RT generates a par bond value at default so that RT and RFV generate very similar credit spreads. Thus, given identical prices ${ }^{14}$, sensitivities still differ: Structural RFV has robust and profound implications for interest rate risk hedging.

Another way of looking at the practical importance of strucural RFV is with reference to this question: Which fraction of classical modified duration should one hedge for high-yield bonds? This is a relevant question for portfolio managers who seem to apply a rule of thumb of hedging about $50 \%$ of the classical modified duration. In Figure 4 we plot model modified durations of A-rated and B-rated bonds against classical modified durations for both the RT and RFV recovery forms. Figure 4 shows that RFV-based hedging of medium to long-term high-yield bonds implies considering only a small (about 50\%) fraction of the classical modified duration of those bonds, in line with prevalent market practice.

\section{Spread-Rate Slope and Recovery Forms}

As shown in Equation 10, there is a link between duration and the sensitivities of credit spreads to the default-free rate. Such sensitivities are the slope coefficients in the regressions of changes in corporate yield spreads on changes in Treasury bond rates performed by Duffee (1998) and by Collin-Dufresne, Goldstein, and Martin (2001).

\footnotetext{
${ }^{14}$ Identical prices can obtained for example by $a d-h o c$ calibration of the recovery rate parameter across different recovery forms.
} 
Duffee (1998) considers monthly data (January 1985 through March 1995) for noncallable bonds issued by US industrial, utility, and financial firms, and performs regressions by rating group in which the effect of the default-free term structure slope is controlled for. He finds that corporate bond yield spreads move inversely with short default-free rates (the 3-month Treasury yield) and that the inverse relation is stronger for lower-quality bonds. Collin-Dufresne, Goldstein, and Martin (2001) consider monthly data (July 1988 through December 1997) for noncallable bonds issued by US industrial firms, and perform regressions by leverage as well as by rating group in which they control for the effect of several structural model determinants of credit spread changes (including the default-free term structure slope). Consistent with the empirical findings of Duffee (1998), they find that an increase in the default-free rate (the 10-year Benchmark Treasury yield) lowers the credit spread for all bonds. Furthermore, the sensitivity to default-free rates increases monotonically across both leverage and rating groups ${ }^{15}$.

In summary, there is robust empirical evidence that the regression coefficient of the credit spread changes on the default-free rate level changes becomes more negative as credit quality decreases. Collin-Dufresne, Goldstein, and Martin (2001) explain this finding by noting that an increase in asset value drift decreases the risk-neutral probability of default, and that the closer firms are to their default threshold, the more sensitive they are to this change. In Leland and Toft (1996) and Acharya and Carpenter (2002) the empirical evidence is matched by relaxing the assumption of an exogenous boundary at default.

We emphasize a recovery-form-based explanation that, together with the drift-based and endogenousdefault-based arguments, can greatly help to understand the empirical spread-rate slope across rating groups. We start by rearranging Equation 10 to note that spread-rate slope is related to duration (see also Acharya and Carpenter (2002), Equation 19, p. 1370):

$$
\begin{aligned}
\frac{d s_{W}}{d y} & =\frac{\frac{d p_{W} / p_{W}}{d y}}{\frac{d p_{W} / p_{W}}{d y_{W}}}-1 \\
& =\frac{\text { modified duration }}{\text { classical modified duration }_{W}}-1
\end{aligned}
$$

If modified duration is low, then credit spread sensitivity $\frac{d s_{W}}{d y}$ must be quite negative. As we have shown in the previous section, RFV modified duration is low when default is imminent,

\footnotetext{
${ }^{15}$ Dynkin, Hyman, and Konstantinovsky (2004) focus on more recent daily data and find similar results in performing regressions by rating group on 10-year Treasury yield changes.
} 
because bondholders expect to soon receive a default-free-rate-insensitive payoff. It follows that, under RFV, credit spread sensitivity to default-free rates becomes more negative as credit quality decreases. This is not the case under recovery forms that specify a default-free-rate-sensitive payoff at default.

This point is best highlighted by the plot in Figure 5. It plots the model credit spread sensitivity to default-free rates versus Moody's rating groups (the range is B through Aaa) for a generic $8.00 \%$ coupon 20-year bond using both the RFV and RT recovery forms-the default-free term structure is flat at the $8.00 \%$ rate and constant. In Figure 5 we also report the slope coefficients in the regressions of changes in long-dated (more than 12 years to maturity) corporate yield spreads on changes in the 10-year Benchmark Treasury yields performed by Collin-Dufresne, Goldstein, and Martin (2001) across the same rating groups (see the fifth row in their Table III, Panel C, p. 2189). RFV sensitivities return a close match of the shape of the empirical spread-rate slope curve. This is especially true for the low-credit-grade area: RFV is able to reproduce the sharp increase in slope magnitude from the the $\mathrm{Ba}$ grade to the $\mathrm{B}$ grade as the model sensitivity level goes from $-24 \%$ to $-43 \%$. For low-grade bonds, the striking evidence in Figure 5 is that a simple structural RFV model predicts spread-rate slope levels that are very similar with those observed empirically. A conclusion from such graphical evidence is that typical recovery forms in exogenous-default structural models rather than exogeneity itself may be the real target of criticism as far as the spread-rate slope pattern is concerned.

\section{Spreads, Default-Free Term Structure, and Recovery Forms}

The vast majority of corporate bonds pay coupons. For coupon bonds we compare credit spreads generated by different recovery forms using the base case model. This is done across credit rating classes and various maturities.

We consider a hypothetical semiannual coupon-paying bond under three different annual coupon rate scenarios with the constant interest rate fixed at $8.00 \%: 1$ ) $\left.8.00 \%(\text { par bond })^{16}, 2\right) 12.00 \%$ (premium bond), and 3) $4.50 \%$ (discount bond).

Results are found in Table III for 6 different credit rating classes and three maturities $(2,10$, and 30-year). In the top three credit rating classes (Aaa, Aa, A) the recovery form does not make much difference. This follows from default being an extremely unlikely event. Relative to the RT

\footnotetext{
${ }^{16}$ Of course the defaultable bonds would not be trading at par due to default risk, however we use the terminology to distinguish among the other cases.
} 
case, RFV spreads can be larger or smaller depending on whether the bonds are at a premium or discount: if $c>8 \%$, RT generates a premium bond value at default so that RT yields a lower spread than RFV does and viceversa if $c<8 \%$. If $c \simeq 8 \%$, RT generates a par bond value at default so that RT and RFV generate a very similar spread. Indeed, in the par bond case RFV and $\mathrm{RT}$ are virtually the same ${ }^{17}$. In the lowest three credit rating classes (Baa, Ba, B) the recovery form does make a significant difference. For high coupon bonds we see that the RFV assumption can noticeably produce larger spreads versus the RT case, especially as the credit rating worsens and the maturity increases. For the 10-year maturity B-rated premium bond RFV produces a spread of 387 bps versus 320 bps for the RT case.

How do the different recovery forms affect pricing in the presence of stochastic default-free interest rates possibly correlated with the default process? In answering to this question we use a default-free term structure model that enjoys the following three properties: 1) It enables the examination of how different initial default-free yield curve shapes can affect credit risk pricing across the different recovery forms; 2) It models the empirical evidence of a negative relationship between default-free interest rate levels and credit spreads (e.g. Duffee (1998) and Collin-Dufresne, Goldstein, and Martin (2001)); 3) It has multifactor dynamics as advocated by a vast majority of the empirical fixed-income literature.

We consider a simple two-factor admissible affine term structure model (see Dai and Singleton (2000) ). The short rate path $r(t)$ is assumed as the sum of two stochastic factors, $l(t)$ and $s(t)$, and a deterministic factor $g(t)$. The dynamic system of equations, under the risk-neutral measure, is

$$
\begin{aligned}
d l(t) & =-\kappa_{l} l(t) d t+\sigma_{l} d z_{l}^{Q} \\
d s(t) & =-\kappa_{s} s(t) d t+\sigma_{s} d z_{s}^{Q} \\
r(t) & =g(t)+l(t)+s(t)
\end{aligned}
$$

where $E\left(d z_{l}^{Q} d z_{s}^{Q}\right)=\rho_{l s} d t, E\left(d z_{l}^{Q} d z_{V}^{Q}\right)=\rho_{l V} d t, E\left(d z_{s}^{Q} d z_{V}^{Q}\right)=\rho_{s V} d t$ and the initial values of both $l$ and $s$ are equal to zero. By making the deterministic term, $g(t)$, time dependent we can calibrate the model to the initial yield curve. A full description of this particular specification as well its solution and calibration procedure can be found in the Appendix.

\footnotetext{
${ }^{17}$ In the Huang and Huang (2003) paper the authors assume a coupon of $8.162 \%$ in their calibration exercises. This corresponds to a par coupon if yields are computed assuming semiannually compounding. Therefore, although they price bonds in their base case using a RT assumption, their RT bond prices approximate RFV bond prices (but not sensitivities).
} 
Implementing the model requires values for the parameters which are assumed constant. In two-factor Gaussian models as the one described, typically one factor can be thought of as the interest rate level factor while the other factor can be interpreted as a slope factor. The level factor is likely the one with a considerably smaller reversion parameter value, indeed usually close to zero. Using the estimates of Brown and Schaefer (2000) from US Treasury STRIP data we set the reversion parameters $\kappa_{l}=0.0393$ and $\kappa_{s}=0.2060$, thus considering $l(t)$ as the level factor and $s(t)$ the slope factor. For the volatility parameters we set $\sigma_{l}=0.010$ and $\sigma_{s}=0.015$, values found in both Brown and Schaefer (1994) and He (2000). We set the term structure correlation parameter, $\rho_{l s}$, equal to -0.336 as estimated by Brown and Schaefer (2000). Using our own estimates from a subset of companies and relevant interest rate data we set $\rho_{l V}=-0.15$ and $\rho_{s V}=0.00$. Ideally we would like these latter correlation parameters to vary by credit rating, but given the size of data which the estimates would have been taken from we consider only one value.

We price defaultable bonds by jointly simulating the firm value process found in (1) and the interest factor processes. The two different recovery forms (RT and RFV) are taken into account when determining cash flows path by path. Details of the simulation procedure and the appropriate techniques used for reducing pricing bias are discussed in the Appendix. We examine 4 different initial default-free curve shapes in terms of the instantaneous forward rate across different maturities: 1) flat curve; 2) upward-sloping curve; 3) humped-shape curve; and 4) downward-sloping curve. The curves are chosen such that the average forward rate over the first ten years is equal to $8 \%$, thus comparable to our base case results with a constant interest rate of $8 \%$. Figure 6 plots the 4 different term structure shapes. Details on how the yield curves are produced using the Nelson and Siegel (1987) methodology is found in the Appendix.

Table IV shows the results in terms of basis point spreads over the default-free promised yield corresponding to the particular interest rate environment. Given an initial flat default-free curve the spreads are little unchanged from our base case result with constant interest rates, despite the fact that the firm value process is correlated with the interest rate process.

For the other three default-free curve shapes the form of the recovery assumption can affect pricing significantly. This is true even if the coupon rate of the bond is not markedly high or low. In the upward-sloping default-free yield curve, the default-free yields are: $4.67 \%$ (2-year), $8.00 \%$ (10-year), and $9.07 \%$ (30-year). In such a scenario, higher long-dated interest rates decrease the recovery value under an RT assumption on a relative basis versus RFV. For the short-dated bond the RFV spread is slightly higher than the RT spread in the B-rated bond due to the coupon of the bond considered being at a significant premium. In the medium term bond, while the bond 
coupon rate is the same relative to the default-free yield the RT spread is higher than RFV, by up to 30 basis points for the B-rated bond.

In the humped-shape default-free curve, the default-free yields are: 9.46\% (2-year), $8.25 \%$ (10year), and $7.74 \%$ (30-year). The results in this scenario are similar to the flat curve scenario since the forward rates assumed flatten out to a constant $7.00 \%$ after the humped-shape rise in the early maturities. The positive difference between the RFV and RT assumptions in the 2 and 10-year case, even though the hypothetical bond would be a discount coupon bond, can be attributed to the higher interest rates assumed in the shorter maturities making any immediate recovery attained in an RFV setting worth relatively less. The difference between the two forms increases as the maturity increases to 30 years as the bond considered becomes a premium coupon bond.

In the downward-sloping default-free curve, the default-free yields are: 9.59\% (2-year), 8.36\% (10-year), and $6.07 \%$ (30-year). This scenario generates the opposite effects seen in the upward sloping scenario: Lower interest rates increase the recovery value under an RT assumption on a relative basis versus RFV. Indeed, for the medium term bonds RFV produces a slightly higher spread compared with the RT assumption despite the fact that the bond is at slight discount to the promised default-free yield. In the case of the 30-year maturity bond the significant premium of the coupon rate versus the default-free yield ( $8.00 \%$ versus $6.07 \%)$ exacerbates the difference between RFV and RT spreads.

Two observations emerge from our analysis under a stochastic interest rate setting. First, our base case results, though assuming constant interest rates, are generally robust as long as the default-free yield curve is not too extensively upward or downward-sloping. As it is visually evident from comparing the 'par bond' columns of credit spreads in Table III with the 'flat curve' columns of credit spreads in Table IV, using the closed-form solutions presented earlier can be done with confidence in defaultable debt analysis in many interest rate environments. Second, while the coupon premium/discount effect is strong, the default-free curve shape can also affect how the recovery form influences model credit spreads. Ceteris paribus, in an upward-sloping curve credit spreads under RT will be higher than RFV credit spreads, while the opposite holds in a downwardsloping yield curve. This has a clear implication whenever exogenous boundary structural credit risk models are used for relative valuation and risk management. In addition, these results are potentially important for researchers doing empirical work with such models. Empirically tests of such models use individual corporate bond price data and they are often based on the study of the prediction errors. Understanding the source of these errors is necessary if we would like to improve on current structural models. However, as these studies are typically done over a long period of 
time, the term structure setting could vary considerably from one period to another. If recovery forms have an impact on model spreads in a way which depend on both the level and the slope of the default-free term structure of interest rates, it is possible that conclusions from such studies may be affected due to the recovery form one is assuming within the model.

\section{Conclusion}

The recovery form specifies the way of valuing payments to bondholders when default occurs. Under $\mathrm{RFV}$, bondholders with the same seniority receive the same fraction of par at default regardless of remaining maturity. Although RFV is consistent with bond indenture language, US bankruptcy law, and defaulted bond values, it has not been studied yet in the context of structural credit risk models.

Within a parsimonious structural model we show that RFV explains two important stylized facts related to hedging high-yield bonds against default-free rate changes: i) low-credit-quality bonds have low modified durations, and ii) credit spread sensitivity to default-free rates becomes more negative as credit quality decreases. RFV offers a simple explanation of these two facts. When default is likely, bondholders focus on what they will get at default and the RFV payment at default is independent from default-free rates. By contrast, RT, the typical recovery form used in the literature (it states that bondholders get at default a fraction of the default-free equivalent of the risky bond) is not able to match the two stylized facts because it assumes a payment at default that depends negatively on default-free rates. Typical recovery forms in exogenous boundary structural models rather than exogeneity itself may be the target of criticism for the failure of explaining the two important stylized facts.

Recovery forms also exert influence on the empirical analysis of structural credit risk models. There is an interaction between the default-free term structure (level and slope) and recovery form in determining model credit spreads. If the curve is at the rate level that makes the default-free equivalent bond trade at par, RFV and RT credit spreads are equal. Given a curve that is centered at the rate level that makes the default-free equivalent bond trade at par, if the curve is upward (downward) sloping, RFV credit spreads are lower (higher) than RT credit spreads as the RFV payment at default is worth more (less) than the RT payment. Since the term structure level and slope in data are dynamic, the time series of credit spreads predicted across RFV and RT will be different. In turn, the recovery form plays an important role in the empirical validation of structural credit risk models.

Our research has direct relevance for the relative valuation and risk management of low-credit 
quality corporate debt and related derivatives. An interesting topic for future research is the empirical validation of the testable RFV restrictions on pricing and hedge ratios ${ }^{18}$. Finally, two important applications of structural RFV can be explored in future research. Firstly, structural RFV is a natural assumption for convertible bond pricing models, as they necessitate the consideration of structural credit risk. Secondly, while for many firms the promised yield spread can provide a good approximation for their cost of debt, for firms with a significant probability of default this can substantially overestimate the expected return on debt ${ }^{19}$. Structural RFV can be used to produce a clean measure of the cost of debt from corporate credit spreads.

\footnotetext{
${ }^{18}$ See for example Schaefer and Strebulaev (2003).

${ }^{19}$ See for example Cooper and Davydenko (2004).
} 


\section{Table I: Worldcom Bonds: Prices Leading up to Bankruptcy}

Shown below are the prices of 9 selected Worldcom bonds with final maturity shown. All bonds are senior unsecured debt. The official initial default event date defined by when Worldcom misses an interest payment is 15 July, 2002. The Chapter 11 bankruptcy filing occurs on 21 July, 2002. On 26 June, 2002 it became public information that the firm had concealed $\$ 3.9$ billion of losses for more than a year.

\begin{tabular}{|c|c|c|c|c|c|c|}
\hline Bond Maturity & 31-Jan-02 & 28-Feb-02 & 28-Mar-02 & 30-Apr-02 & 31-May-02 & 18-Jun-02 \\
\hline 18-May-03 & 103.27 & 99.69 & 95.62 & 75 & 84.5 & 81 \\
\hline 01-Apr-04 & 103.06 & 98.50 & 91.47 & 60 & 73.5 & 70 \\
\hline 15-Aug-05 & 99.22 & 96.45 & 86.51 & 50 & 57 & 54.5 \\
\hline 15-Jan-06 & 100.00 & 97.66 & 87.40 & 49 & 56 & 53 \\
\hline 01-Apr-07 & 101.96 & 97.80 & 86.65 & 45.5 & 54 & 49.5 \\
\hline 15-May-10 & 103.09 & 101.06 & 88.83 & 48 & 50 & 47.5 \\
\hline 15-May-11 & 97.68 & 96.35 & 83.88 & 47 & 49 & 46.5 \\
\hline 15 -Aug-28 & 85.28 & 82.31 & 69.66 & 42 & 38.5 & 39 \\
\hline 15-May-31 & 99.05 & 96.12 & 80.66 & 44 & 43 & 42 \\
\hline Bond Maturity & 21-Jun-02 & 25-Jun-02 & 26-Jun-02 & 27-Jun-02 & 15-Jul-02 & 22-Jul-02 \\
\hline 18-May-03 & 75 & 68.5 & 14 & 17 & 14.25 & 13.25 \\
\hline 01-Apr-04 & 61.5 & 57.5 & 11.5 & 13.75 & 14.25 & 13.25 \\
\hline 15-Aug-05 & 49 & 46.5 & 11.5 & 13.75 & 14.25 & 13.25 \\
\hline 15-Jan-06 & 48.5 & 45 & 11.5 & 13 & 14 & 13.25 \\
\hline 01-Apr-07 & 45.5 & 42 & 11.5 & 13 & 14 & 13.25 \\
\hline 15-May-10 & 44 & 42 & 11.25 & 14 & 14 & 13.25 \\
\hline 15-May-11 & 43.5 & 41 & 11.5 & 13.5 & 14 & 13.25 \\
\hline 15-Aug-28 & 37.5 & 36.5 & 11 & 14 & 14 & 13.25 \\
\hline 15-May-31 & 40 & 38 & 11.25 & 13 & 14 & 13.25 \\
\hline
\end{tabular}




\section{Table II: Parameter Values for Various Credit Grades}

The table shows the leverage ratio and asset volatility parameters across credit ratings used for computing model spreads for representative companies of that particular credit rating. The numbers are taken from Davydenko and Strebulaev (2002). Parameters used in the model which are invariant across credit rating classes are taken from Huang and Huang (2003).

\begin{tabular}{ccc}
\hline Credit Rating & Leverage Ratio & Asset Vol \\
\hline Aaa & .12 & .22 \\
Aa & .15 & .24 \\
A & .29 & .24 \\
Baa & .36 & .25 \\
Ba & .45 & .28 \\
B & .64 & .37 \\
& & \\
\hline \hline
\end{tabular}




\section{Table III: Recovery Form and Credit Spreads: Constant Interest Rates}

Calculated yield spreads are shown in basis points across different credit rating classes for 2, 10, and 30-year maturities using a first passage defaultable debt model. Parameter assumptions are described in Table II and Section 2. The hypothetical bond pays a semi-annual coupon at an annual rate of either 8.00\% (Par Bond), 12.00\% (Premium Bond), or $4.50 \%$ (Discount Bond). The recovery assumptions considered are: 1) Recovery of Treasury (RT), and 2) Recovery of Face Value (RFV).

\begin{tabular}{|c|c|c|c|c|c|c|}
\hline \multicolumn{7}{|c|}{ Panel A: 2-Year Maturity } \\
\hline & \multicolumn{2}{|c|}{ Par Bond } & \multicolumn{2}{|c|}{ Premium Bond } & \multirow{2}{*}{$\begin{array}{c}\text { Discount } \\
R T\end{array}$} & \multirow{2}{*}{$\begin{array}{l}\text { Bond } \\
R F V\end{array}$} \\
\hline & $R T$ & $R F V$ & $R T$ & $R F V$ & & \\
\hline Aaa & 0.00 & 0.00 & 0.00 & 0.00 & 0.00 & 0.00 \\
\hline $\mathrm{Aa}$ & 0.00 & 0.00 & 0.00 & 0.00 & 0.00 & 0.00 \\
\hline A & 0.00 & 0.00 & 0.00 & 0.00 & 0.00 & 0.00 \\
\hline Baa & 0.05 & 0.05 & 0.04 & 0.04 & 0.04 & 0.04 \\
\hline $\mathrm{Ba}$ & 2.97 & 3.07 & 2.91 & 3.05 & 3.05 & 3.08 \\
\hline $\mathrm{B}$ & 224.73 & 229.62 & 221.29 & 233.33 & 228.01 & 226.08 \\
\hline \multicolumn{7}{|c|}{ Panel B: 10-Year Maturity } \\
\hline & \multicolumn{2}{|c|}{ Par Bond } & \multicolumn{2}{|c|}{ Premium Bond } & Discount & Bond \\
\hline & $R T$ & $R F V$ & $R T$ & $R F V$ & $R T$ & $R F V$ \\
\hline Aaа & 0.07 & 0.07 & 0.06 & 0.07 & 0.08 & 0.07 \\
\hline $\mathrm{Aa}$ & 0.78 & 0.79 & 0.70 & 0.76 & 0.87 & 0.83 \\
\hline A & 10.58 & 10.76 & 9.77 & 10.78 & 11.55 & 10.74 \\
\hline Baa & 27.67 & 28.13 & 25.94 & 28.97 & 29.79 & 27.12 \\
\hline $\mathrm{Ba}$ & 83.55 & 84.90 & 80.08 & 91.46 & 87.82 & 76.88 \\
\hline B & 319.45 & 324.31 & 320.14 & 386.64 & 318.59 & 250.63 \\
\hline \multicolumn{7}{|c|}{ Panel C: 30-Year Maturity } \\
\hline & \multicolumn{2}{|c|}{ Par Bond } & \multicolumn{2}{|c|}{ Premium Bond } & Discount & Bond \\
\hline & $R T$ & $R F V$ & $R T$ & $R F V$ & $R T$ & $R F V$ \\
\hline Aaa & 2.67 & 2.70 & 2.39 & 2.89 & 3.18 & 2.35 \\
\hline $\mathrm{Aa}$ & 8.14 & 8.22 & 7.49 & 9.25 & 9.33 & 6.36 \\
\hline A & 27.13 & 27.33 & 26.01 & 33.12 & 29.18 & 16.94 \\
\hline Baa & 46.20 & 46.50 & 45.06 & 58.28 & 48.30 & 25.58 \\
\hline $\mathrm{Ba}$ & 92.70 & 93.20 & 92.27 & 122.54 & 93.49 & 42.73 \\
\hline B & 249.71 & 250.76 & 255.22 & 364.25 & 239.21 & 80.97 \\
\hline
\end{tabular}




\section{Table IV: Recovery and Credit Spreads: Stochastic Interest Rates}

Calculated yield spreads are shown in basis points across different credit rating classes for 2, 10, and 30-year maturities using the first passage firm value model described in Section 2 combined with the default-free multifactor term structure model described in Section 5. The parameters for the firm value model are described in Table II while the parameters for the term structure model are described in Section 5. We consider a hypothetical bond paying a semi-annual coupon at an annual rate of $8.00 \%$. We consider four different initial interest rate environments as described in the Appendix: 1) Flat Curve, 2)Upward Sloping Curve, 3)Humped Shape Curve, and 4)Downward Sloping Curve. The respective default-free promised yields for the 2,10, and 30-year maturity bonds under the different environments are: 1)8.00\%(2-year), 8.00\%(10-year), $8.00 \%$ (30-year); 2)4.67\%, 8.00\%, 9.07\%; 3)9.46\%, 8.25\%, 7.74\%; and 4)9.59\%, 8.36\%, 6.07\%. The recovery assumptions considered are: 1) Recovery of Treasury (RT), and 2) Recovery of Face Value (RFV).

\begin{tabular}{|c|c|c|c|c|c|c|c|c|}
\hline \multicolumn{9}{|c|}{ Panel A: 2-Year Maturity } \\
\hline & \multicolumn{2}{|c|}{ Flat Curve } & \multicolumn{2}{|c|}{ Upward Sloping } & \multicolumn{2}{|c|}{ Humped Shape } & \multicolumn{2}{|c|}{ Downward Sloping } \\
\hline & $R T$ & $R F V$ & $R T$ & $R F V$ & $R T$ & $R F V$ & $R T$ & $R F V$ \\
\hline Aaa & 0.00 & 0.00 & 0.00 & 0.00 & 0.03 & 0.03 & 0.02 & 0.02 \\
\hline $\mathrm{Aa}$ & 0.00 & 0.00 & 0.00 & 0.00 & 0.02 & 0.02 & 0.00 & 0.00 \\
\hline $\mathrm{A}$ & 0.00 & 0.00 & 0.00 & 0.00 & 0.02 & 0.02 & 0.02 & 0.02 \\
\hline Baa & 0.00 & 0.00 & 0.17 & 0.17 & 0.07 & 0.07 & 0.02 & 0.02 \\
\hline $\mathrm{Ba}$ & 2.53 & 2.59 & 4.57 & 4.71 & 2.07 & 2.11 & 2.18 & 2.22 \\
\hline $\mathrm{B}$ & 226.97 & 231.70 & 279.29 & 289.08 & 204.74 & 205.77 & 204.90 & 207.65 \\
\hline \multicolumn{9}{|c|}{ Panel A: 10-Year Maturity } \\
\hline & \multicolumn{2}{|c|}{ Flat Curve } & \multicolumn{2}{|c|}{ Upward Sloping } & \multicolumn{2}{|c|}{ Humped Shape } & \multicolumn{2}{|c|}{ Downward Sloping } \\
\hline & $R T$ & $R F V$ & $R T$ & $R F V$ & $R T$ & $R F V$ & $R T$ & $R F V$ \\
\hline Aaa & 0.25 & 0.25 & 0.21 & 0.21 & 0.16 & 0.16 & 0.03 & 0.03 \\
\hline Aa & 0.93 & 0.94 & 0.84 & 0.81 & 0.64 & 0.67 & 0.41 & 0.44 \\
\hline A & 9.98 & 10.18 & 10.27 & 9.78 & 10.33 & 10.70 & 9.99 & 10.43 \\
\hline Baa & 26.75 & 27.24 & 27.01 & 25.45 & 26.82 & 27.94 & 24.52 & 25.61 \\
\hline $\mathrm{Ba}$ & 83.22 & 84.22 & 82.65 & 76.27 & 76.28 & 79.27 & 77.11 & 80.25 \\
\hline $\mathrm{B}$ & 315.85 & 318.48 & 328.43 & 299.58 & 307.38 & 317.68 & 306.73 & 315.66 \\
\hline \multicolumn{9}{|c|}{ Panel A: 30-Year Maturity } \\
\hline & \multicolumn{2}{|c|}{ Flat Curve } & \multicolumn{2}{|c|}{ Upward Sloping } & \multicolumn{2}{|c|}{ Humped Shape } & \multicolumn{2}{|c|}{ Downward Sloping } \\
\hline & $R T$ & $R F V$ & $R T$ & $R F V$ & $R T$ & $R F V$ & $R T$ & $R F V$ \\
\hline Aaa & 3.46 & 3.71 & 1.28 & 1.17 & 4.91 & 5.59 & 17.67 & 23.29 \\
\hline Aa & 9.85 & 10.27 & 3.25 & 2.69 & 13.02 & 14.39 & 31.76 & 43.31 \\
\hline A & 29.63 & 30.68 & 14.64 & 10.77 & 35.51 & 39.76 & 67.72 & 95.29 \\
\hline Baa & 47.74 & 48.88 & 29.14 & 20.54 & 55.31 & 61.88 & 89.52 & 128.47 \\
\hline $\mathrm{Ba}$ & 93.70 & 94.97 & 71.71 & 48.35 & 100.73 & 112.52 & 134.75 & 197.62 \\
\hline $\mathrm{B}$ & 246.70 & 246.03 & 240.81 & 158.81 & 250.35 & 278.83 & 266.79 & 400.51 \\
\hline
\end{tabular}




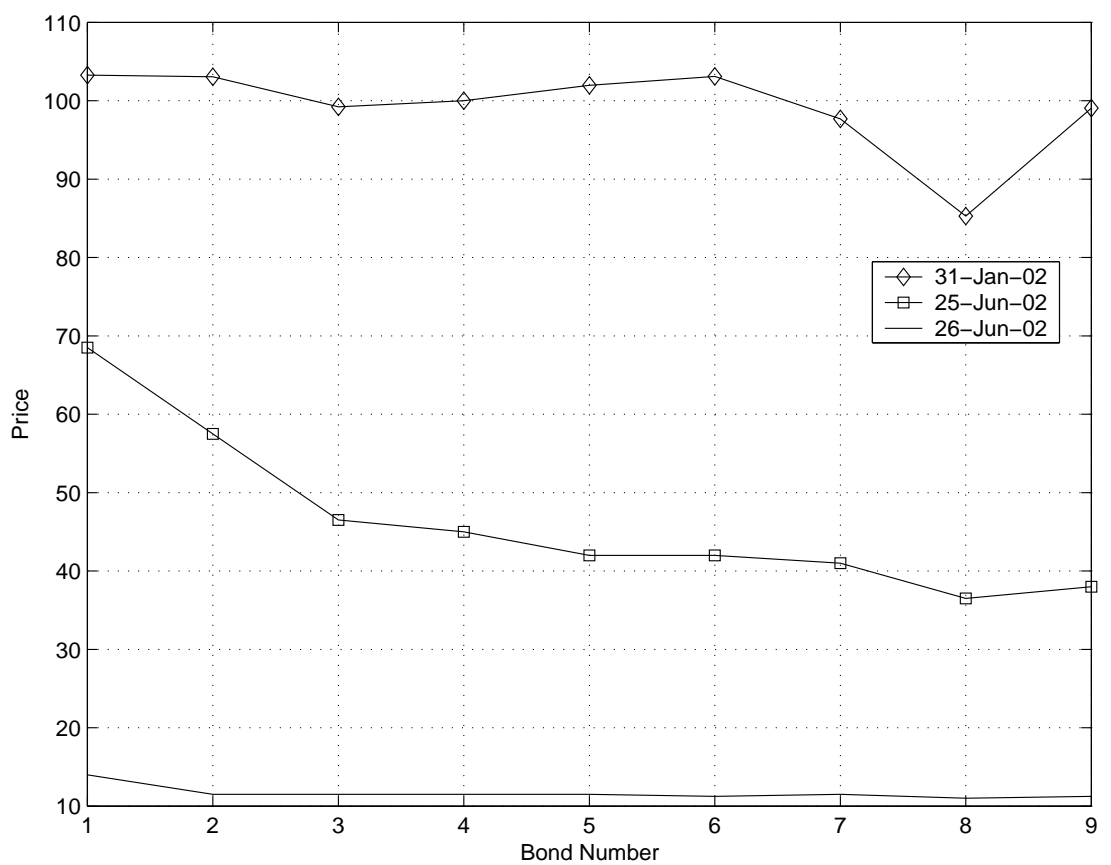

Figure 1: Worldcom Inc. Bond Prices

The plot shows prices for nine bonds issued by Worldcom Incorporated at three different dates leading up to their official default date on 15 July 2002. The bonds are sorted by maturity whose details are found in Table I. 


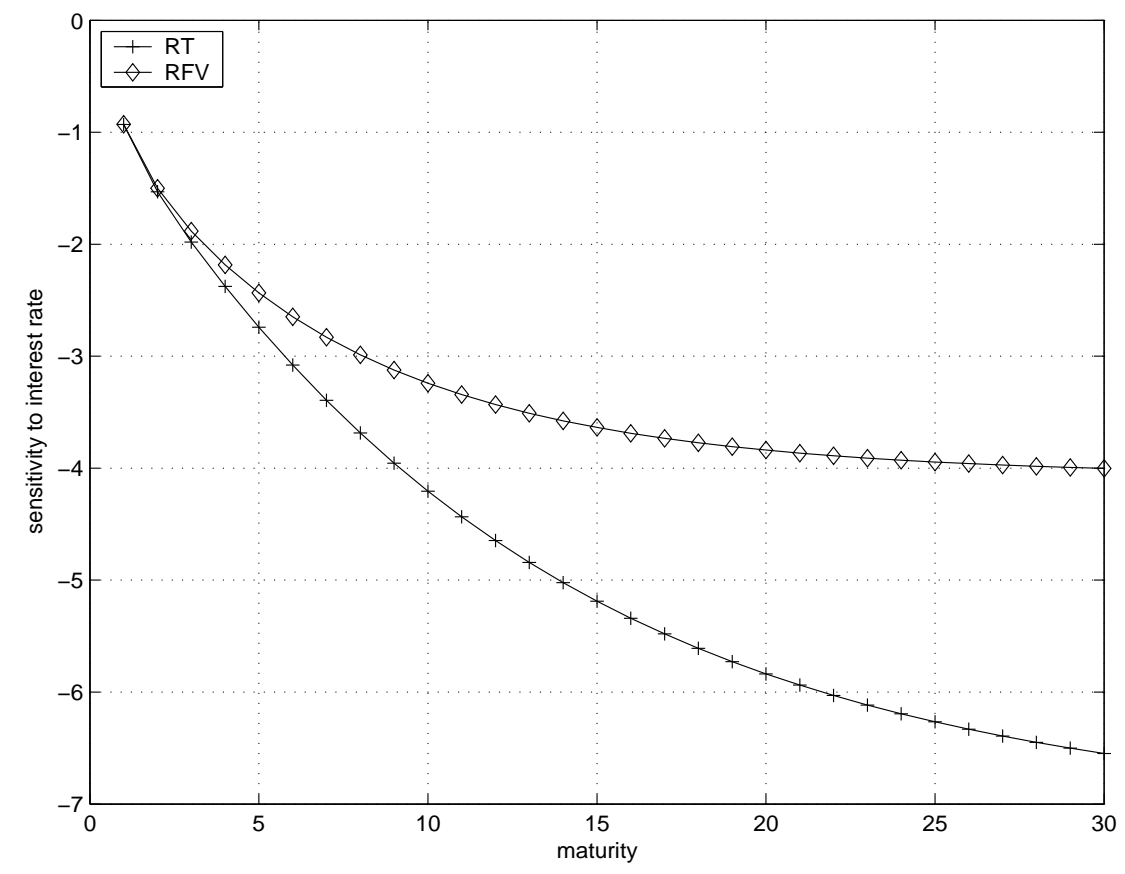

Figure 2: Term Structure of Interest Rate Sensitivity: B Rating

The plot shows the term structure of sensitivities of coupon bond prices to the default-free interest rate for a hypothetical company with a speculative-grade B credit rating using the Recovery of Treasury (RT), and Recovery of Face Value (RFV) recovery assumptions. The negative of the derivative values shown on the y-axis can be interpreted as the dollar duration of the relevant bond. The coupon (8.00\%) is chosen to equal the default-free interest rate. The leverage ratio (64\%) and asset volatility (37\%) parameters are taken from Table II. Other parameters include the constant default-free interest rate $(8.00 \%)$, constant payout ratio $(6.00 \%)$, default boundary (60\% of total liabilities) and expected recovery rate $(51.31 \%)$. 


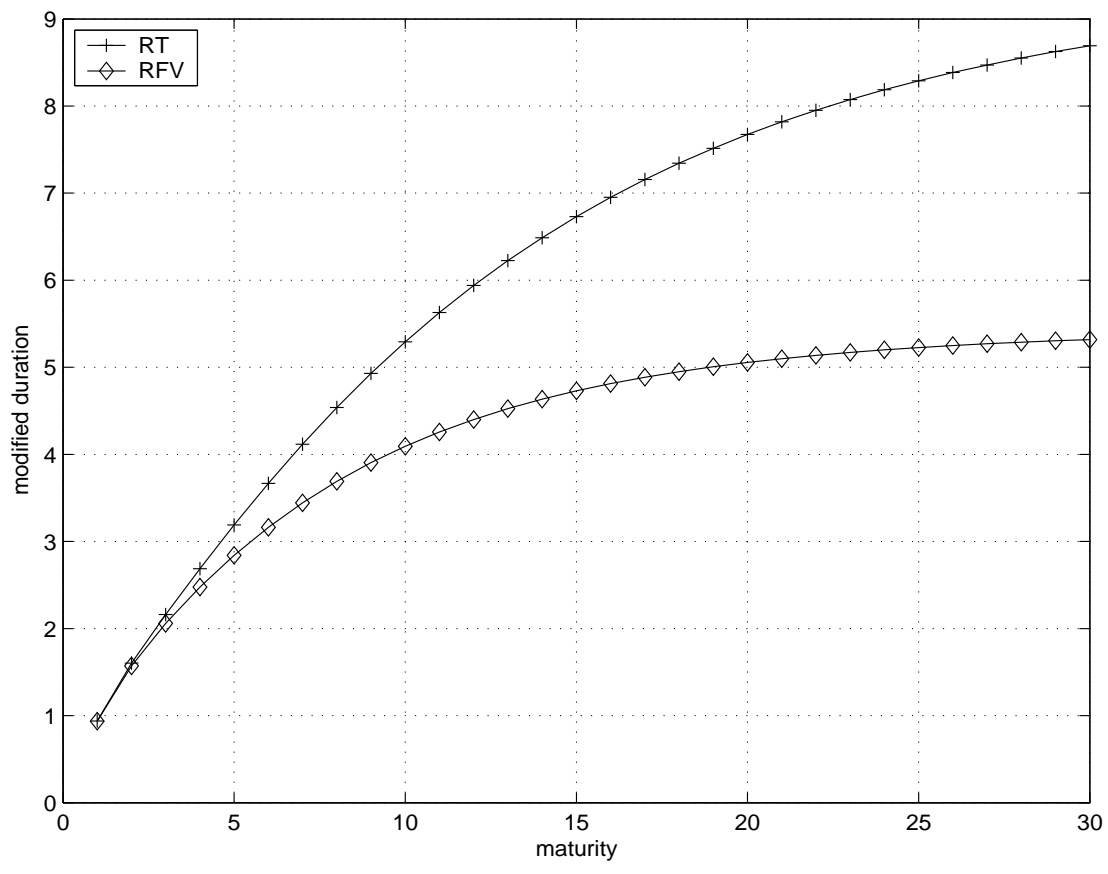

Figure 3: Term Structure of Modified Durations: B Rating

The plot shows the term structure of modified durations for a hypothetical company with a speculative-grade B credit rating using the Recovery of Treasury (RT), and Recovery of Face Value (RFV) recovery assumptions. The modified duration is defined as the negative of the derivative divided by the relevant model price. The coupon $(8.00 \%)$ is chosen to equal the default-free interest rate. The leverage ratio $(64 \%)$ and asset volatility $(37 \%)$ parameters are taken from Table II. Other parameters include the constant default-free interest rate (8.00\%), constant payout ratio $(6.00 \%)$, default boundary (60\% of total liabilities) and expected recovery rate $(51.31 \%)$. 


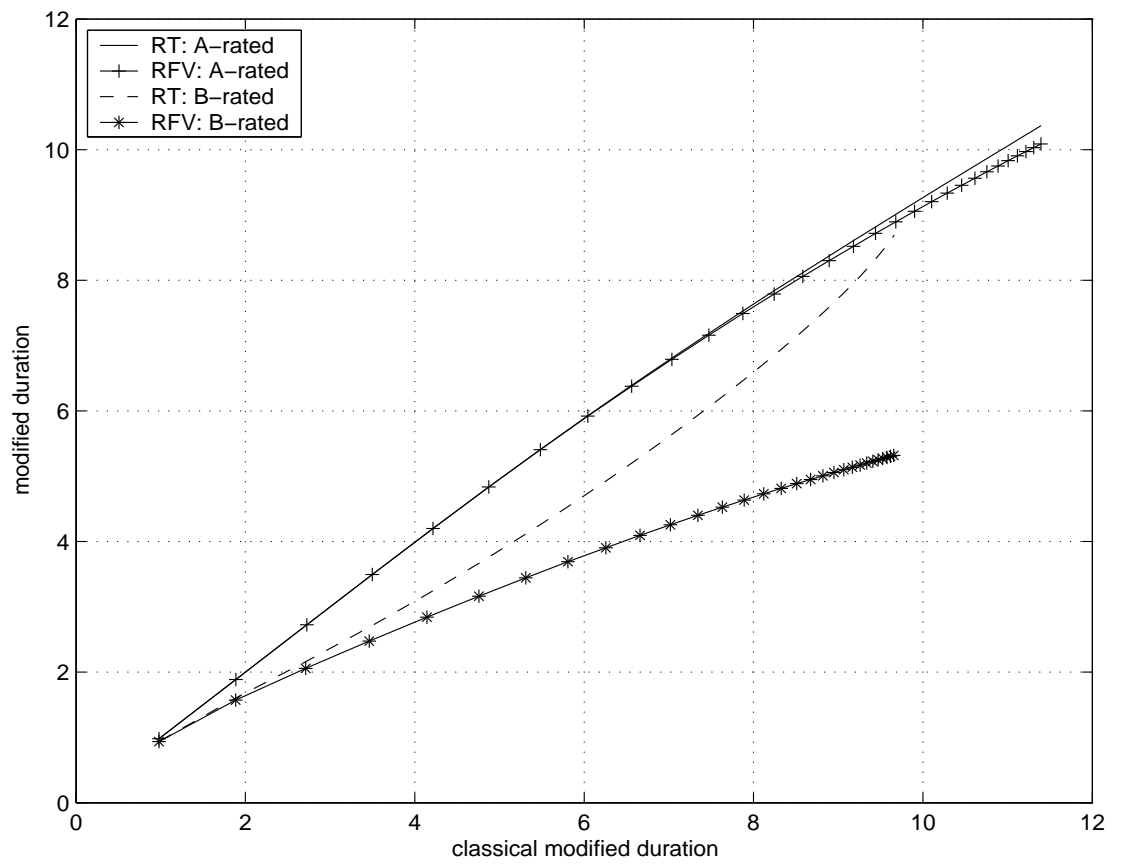

Figure 4: Modified Duration vs. Classical Modified Duration

The plot shows the modified duration graphed against the corresponding classical modified duration for A-rated and B-rated $8.00 \%$ coupon bonds using the Recovery of Treasury (RT) and the Recovery of Face Value (RFV) recovery forms across 30 different maturities $(T=1,2, \ldots, 30)$. The leverage ratio and asset volatility parameters for the different credit ratings come from Table II. The remaining parameters are: default-free interest rate (8.00\%), payout rate $(6.00 \%)$, default boundary (60\% of total liabilities) and expected recovery rate $(51.31 \%)$. Modified duration is defined as the percentage change in the corporate bond price due to a change in the default-free rate (Equation 9). Classical modified duration is defined as the percentage change in the corporate bond price due to a change in the promised yield. The ratio between modified duration and classical modified duration equals one plus the credit spread sensitivity to the default-free rate (Equation 10). 


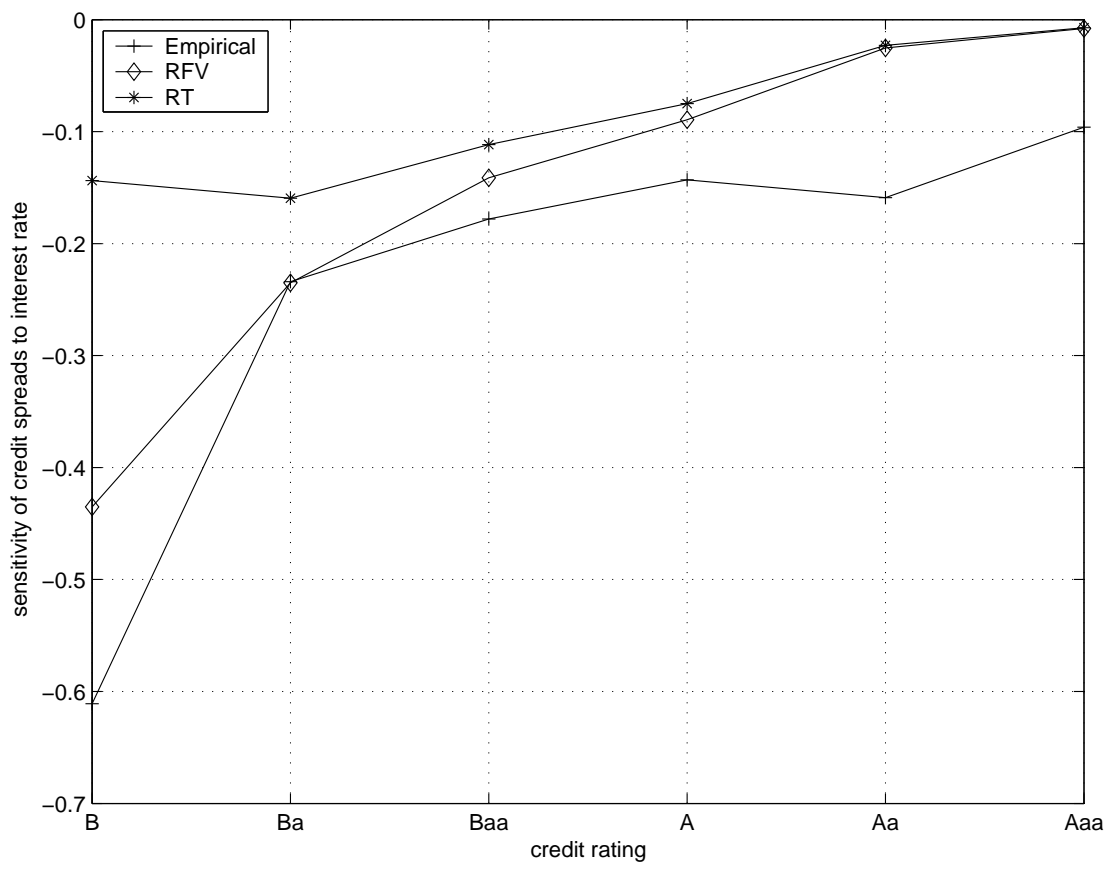

Figure 5: Credit Spread Sensitivity to Interest Rates: Model and Empirical

The plot shows the sensitivity of credit spreads to default-free interest rates against different credit ratings. Model sensitivities are calculated using both the Recovery of Treasury (RT) and Recovery of Face Value (RFV) recovery forms for a generic $8.00 \%$ coupon 20 -year bond. The leverage ratio and asset volatility parameters for the different credit ratings come from Table II. The remaining parameters are: default-free interest rate (8.00\%), payout rate $(6.00 \%)$, default boundary (60\% of total liabilities) and expected recovery rate (51.31\%). The empirical credit spread sensitivities are the slope coefficients in the regressions of changes in long-dated corporate yield spreads on changes in the 10-year Treasury yields performed by Collin-Dufresne, Goldstein, and Martin (2001) across the credit ratings (see the fifth row in their Table III, Panel C, p. 2189). 


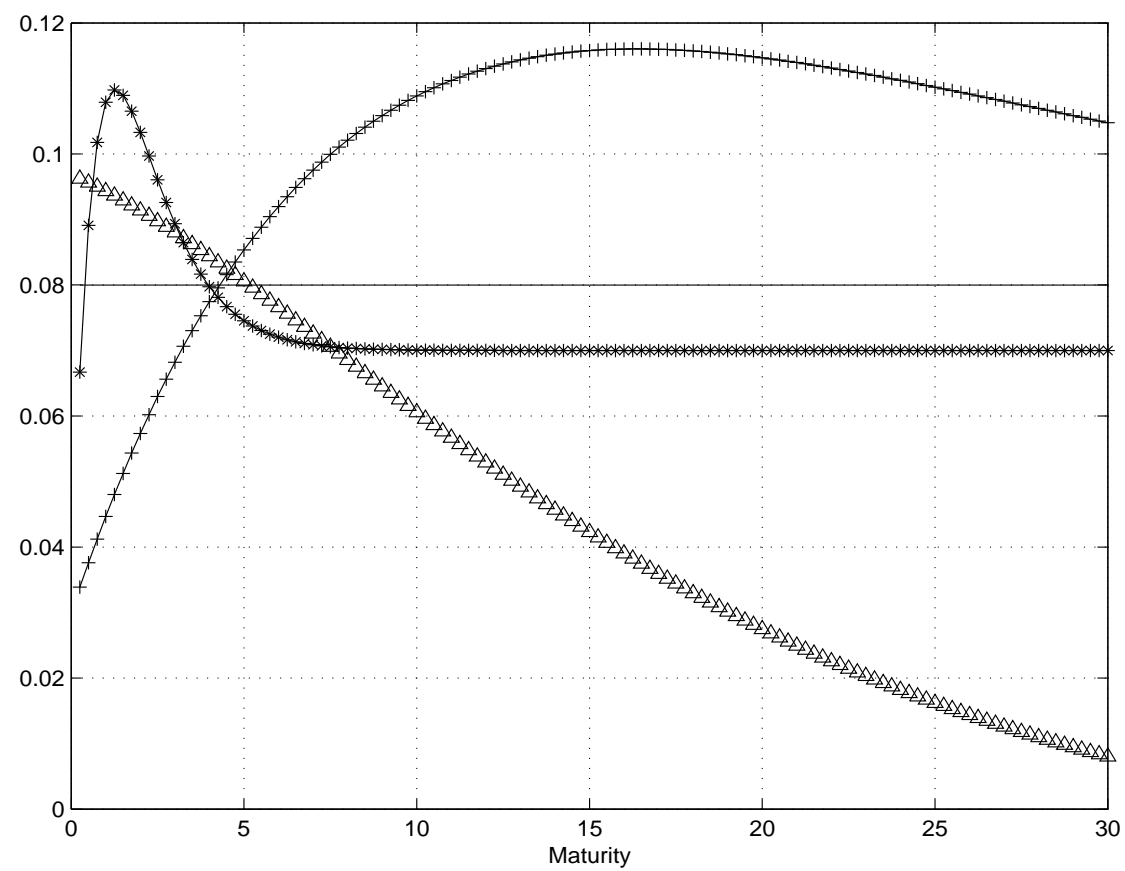

Figure 6: Hypothetical Yield Curve Shapes used in Bond Pricing

The plot shows the 4 different yield curve shapes we assume in comparing defaultable bond pricing in a stochastic interest rate environment. The yield curves are in terms of the instantaneous forward rates and are generated by Nelson and Siegel (1987) methodology using the parameters given in the Appendix. 


\section{APPENDIX}

\section{A Default-Free Term Structure Model Specification}

We describe here the default-free term structure model specification used in Section 5 . The value of a default-free riskless zero coupon bond at time $t$ with maturity date $T$ is

$$
P(t, T)=E_{t}^{Q}\left[\exp \left(-\int_{t}^{T} r(s) d s\right)\right]
$$

where $r(t)$ is the process for instantaneous riskless nominal short rate. We consider a term structure model in the multivariate affine class as described, for example, by Duffie and Kan (1996) and Dai and Singleton (2000). We introduce the two factors, $l(t)$ and $s(t)$, for which, under the risk-neutral probability measure $Q$, we assume:

$$
\begin{aligned}
d l(t) & =-\kappa_{l} l(t) d t+\sigma_{l} d z_{l}^{Q}, \\
d s(t) & =-\kappa_{s} s(t) d t+\sigma_{s} d z_{s}^{Q}, \\
r(t) & =g(t)+l(t)+s(t),
\end{aligned}
$$

where $E\left(d z_{l}^{Q} d z_{s}^{Q}\right)=\rho_{l s} d t$ and the initial values of both $l$ and $s$ are equal to zero, which is their long-run mean. $\kappa_{l}$ and $\kappa_{s}$ are reversion parameters of the two factors, while $\sigma_{l}$ and $\sigma_{s}$ are volatility parameters.

The basic bond valuation equation (A1) becomes

$$
\begin{aligned}
P(t, T)= & E_{t}^{Q}\left[\exp \left(-\int_{t}^{T}(g(u)+l(u)+s(u)) d u\right)\right]= \\
& \exp \left(-\int_{t}^{T} g(u) d u\right) \cdot E_{t}^{Q}\left[\exp \left(-\int_{t}^{T}(l(u)+s(u)) d u\right)\right] .
\end{aligned}
$$

The expectation on the right hand side has a well-known solution form as seen in Duffie and Kan (1996) so we can write the bond value as

$$
P(t, T)=\exp \left(-\int_{t}^{T} g(u) d u\right) \cdot \exp \left[A(T-t)-B_{l}(T-t) l(t)-B_{s}(T-t) s(t)\right]
$$

where after solving the PDE and denoting $T-t=T-t$, we find

$$
\begin{gathered}
B_{l}(T-t)=\frac{1-\exp \left(-\kappa_{l}(T-t)\right)}{\kappa_{l}}, \quad B_{y}(T-t)=\frac{1-\exp \left(-\kappa_{s}(T-t)\right)}{\kappa_{s}}, \\
A(T-t)=\int_{0}^{T-t} A^{\prime}(u) d u \text { where } A^{\prime}(T-t)=\frac{1}{2} \sigma_{l}^{2} B_{l}^{2}(T-t)+\frac{1}{2} \sigma_{s}^{2} B_{s}^{2}(T-t)+\rho_{l s} \sigma_{l} \sigma_{s} B_{l}(T-t) B_{s}(T-t) .
\end{gathered}
$$

We would like to calibrate the model to be able to fit the initial yield curve. The solution to the term structure model (A2)

$$
r(t)=g(t)+\sigma_{l} e^{-\kappa_{l} t} \int_{0}^{t} e^{\kappa_{l} u} d z_{l}(u)+\sigma_{s} e^{-\kappa_{s} t} \int_{0}^{t} e^{\kappa_{s} u} d z_{s}(u)
$$

The time dependent intercept $g(t)$ will embed any information regarding the initial yield curve. From (A4) we can express the initial yield curve as the set of zero coupon bond prices at time 0

$$
P(0, T)=\exp \left[-\int_{0}^{T} g(u) d u+A(T)\right],
$$

since $l(0)=0$ and $s(0)=0$ by construction. Taking logs and differentiating with respect to $T$ on both sides of the equation (A7) and then substituting from (A5)we arrive at

$$
\begin{gathered}
f(0, T)=-\frac{d \log P(0, T)}{d T}, \\
g(T)=-\frac{d \log P(0, T)}{d T}+\frac{d A(T)}{d T}= \\
f(0, T)+\frac{1}{2} \sigma_{l}^{2} B_{l}^{2}(T)+\frac{1}{2} \sigma_{s}^{2} B_{s}^{2}(T)+\rho_{l s} \sigma_{l} \sigma_{s} B_{l}(T) B_{s}(T),
\end{gathered}
$$


where $f(0, T)$ is the initial instantaneous forward rate curve. We can substitute this term into equation (A6) to arrive at our new expression for the short rate path

$$
\begin{aligned}
r(t)= & f(0, t)+\frac{1}{2} \sigma_{l}^{2} B_{l}^{2}(t)+\frac{1}{2} \sigma_{s}^{2} B_{s}^{2}(t)+\rho_{l s} \sigma_{l} \sigma_{s} B_{l}(t) B_{s}(t) \\
& +\sigma_{l} e^{-\kappa_{l} t} \int_{0}^{t} e^{\kappa_{l} u} d z_{l}(u)+\sigma_{s} e^{-\kappa_{s} t} \int_{0}^{t} e^{\kappa_{s} u} d z_{s}(u)
\end{aligned}
$$

From this expression it is clear how the short rate path used to value all interest rate sensitive claims can be calibrated to initial market data - via the forward rate curve.

\section{B Simulation Pricing Procedure}

This section describes the Monte Carlo simulation procedure used for pricing the defaultable bonds under a stochastic interest rate environment with the term structure model specified above in (11). The simulations are performed on the basis of the Euler discretization of the following continuous-time data generating process:

$$
\begin{gathered}
d l(t)=-\kappa_{l} l(t) d t+\sigma_{l} d z_{l}^{Q}, \\
d s(t)=-\kappa_{s} s(t) d t+\sigma_{s} d z_{s}^{Q}, \\
d x_{t}=\left(r(t)-\delta-\frac{\sigma_{V}^{2}}{2}\right) d t+\sigma_{V} d z_{V}^{Q}, \\
r(t)=g(t)+l(t)+s(t),
\end{gathered}
$$

where $E\left(d z_{l}^{Q} d z_{s}^{Q}\right)=\rho_{l s} d t, E\left(d z_{l}^{Q} d z_{V}^{Q}\right)=\rho_{l V} d t, E\left(d z_{s}^{Q} d z_{V}^{Q}\right)=\rho_{s V} d t$. The initial values of $l(t)$ and $s(t)$ are equal to zero, while the initial value of $x(t)$ is $x_{0}$. Default occurs the first time $x(t)$ hits zero. We employ a Cholesky factorization of the correlation matrix $\boldsymbol{\Sigma}$ of the random processes $z_{i}, i=\{V, l, s\}$ so we can write the system in terms of independent Wiener processes $w_{i}, i=\{V, l, s\}$ :

$$
\mathbf{z}=\mathbf{M w}
$$

and

$$
\mathrm{MM}^{\top}=\boldsymbol{\Sigma},
$$

where $\mathbf{M}$ is a lower triangular matrix.

After we have rewritten the dynamics in terms of the independent processes $w_{i}, i=\{V, l, s\}$ we discretize our continuous time equations at equal time steps $\Delta t$. For $x(t)$, we do a simple Euler discretization. For $l(t)$ and $s(t)$ we discretize their continuous closed-form solutions.

We generate $N(N=100000)$ paths of $x$ and the short rate $r$ using the antithetic variable technique and 52 steps per year. Defaultable bond valuation is attained as follows. First, the promised cash flows would be generated for each path. Second, if default has occurred for a specific path the promised cash flows would be altered in a way specific to the recovery form assumed. Once the default-adjusted cash flow paths have been generated we discount each cash flow path at the relevant riskfree short rate path. That is the rate path which produced the default path associated with the default-adjusted cash flow path. The mean of these $N$ values can be considered the crude Monte Carlo estimated bond price.

The presence of a default boundary implies that the Crude Monte Carlo price suffers an overpricing bias. Once we sample our continuous time processes at discrete time intervals we do not get as many default-triggering "hits" in our simulation as we would expect under our risk-neutral pricing measure. This is due to the fact that for any nonzero time interval discretization induces a bias since many time points at which low values of the variable $x$ could occur are ignored. Narrowing the time step shrinks the bias toward zero, but time steps small enough to produce accurate answers may be computationally quite burdensome. To correct this bias we implement the technique developed by Beaglehole, Dybvig, and Zhou (1997). Their technique draws on the theory of the Brownian bridge. After we have generated the paths for $x(t)$ in our crude simulation we treat each discrete time interval as two ends of a Brownian bridge. We then draw the minimum (as we are interested in $x(t)$ reaching zero) of the path process on the interval using the known theoretical distribution of a Brownian bridge on an interval.

\section{Generating Hypothetical Yield Curves}

We generate 4 yield curve shapes: 1) flat curve; 2) upward-sloping curve; 3) humped-shape curve; and 4) downward sloping curve. We produce curves in terms of the instantaneous forward rate curve. Generating the flat curve 
is straightforward. For the remaining types we used the Nelson and Siegel (1987) methodology which fits term structures using the following form for the initial instantaneous forward rate curve:

$$
f(0, m)=\beta_{0}+\beta_{1} \exp \left(\frac{-m}{u}\right)+\beta_{2}\left(\frac{m}{u} \exp \left(\frac{-m}{u}\right)\right)
$$

where $m$ is a particular maturity point on the yield curve while $\beta_{0}, \beta_{1}$, $\beta_{2}$, and $u$ are parameters. We choose parameters such that the sought for shapes are generated and that the average instantaneous forward rate over the first ten years is equal to 0.08. The curves are shown in Figure 6. The parameter values chosen are as follows:

Flat: $\beta_{0}=0.08, \beta_{1}=0, \beta_{2}=0$

Upward-Sloping: $\beta_{0}=0.08, \beta_{1}=-0.05, \beta_{2}=0.14, u=12.05$

Humped-Shape: $\beta_{0}=0.07, \beta_{1}=-0.04, \beta_{2}=0.143, u=1$

Downward-Sloping: $\beta_{0}=-.01, \beta_{1}=0.1068, \beta_{2}=0.085, u=10.00$ 


\section{References}

Acharya, Viral, and Jennifer Carpenter, 2002, Corporate bond valuation and hedging with stochastic interest rates and endogenous bankruptcy, Review of Financial Studies 15, 1355-1383.

Bakshi, Gurdip, Dilip Madan, and Frank Zhang, 2002, Understanding the role of recovery in default risk models: Empirical comparisons and implied recovery rates, Working Paper, University of Maryland.

Beaglehole, David R., Philip H. Dybvig, and Guofhu Zhou, 1997, Going to extremes: Correcting simulation bias in exotic option valuation, Financial Analyst Journal p. 6268.

Black, Fischer, and John C. Cox, 1976, Valuing corporate securities: Some effects of bond indenture provisions, Journal of Finance 31, 351-367.

Brown, Roger, and Stephen M. Schaefer, 1994, Interest rate volatility and the shape of the term structure, in Mathematical Models in Finance (The Royal Society in Phil. Trans. R. Soc. Land.).

, 2000, Why long term forward interest rates (almost) always slope downwards?, Working Paper, London Business School.

Campi, Luciano, Simon Polbennikov, and Alessandro Sbuelz, 2005, Assessing credit with equity: A CEV model with jump to default, Working Paper, University of Verona.

Campi, Luciano, and Alessandro Sbuelz, 2005, Closed-form pricing of benchmark equity default swaps under the CEV assumption, Finance Letters.

Cathcart, Lara, and Lina El-Jahal, 1998, Valuation of defaultable bonds, Journal of Fixed Income $8,65-78$.

Collin-Dufresne, Pierre, and Robert Goldstein, 2001, Do credit spreads reflect stationary leverage ratios?, Journal of Finance 56, 1929-1957.

— , and J. Spencer Martin, 2001, The determinants of credit spread changes, Journal of Finance 56, 2177-2207.

Cooper, Ian, and Sergei Davydenko, 2004, Using yield spreads to estimate expected returns on debt and equity, LBS Working Paper.

Cornell, Bradford, and Kevin Green, 1991, The investment performance of low-grade bond funds, Journal of Finance 46, 29-48.

Dai, Qiang, and Kenneth J. Singleton, 2000, Specification analysis of affine term structure models, Journal of Finance 55, 1943-1978.

Davydenko, Sergei, 2005, When do firms default? a study of the default boundary, Working Paper, University of Toronto.

— and Ilya Strebulaev, 2002, Strategic behavior, capital structure, and credit risk: An empirical investigation, LBS Working Paper.

Delianedis, Gordon, and Ronald Lagnado, 2002, Recovery assumptions in the valuation of credit derivatives, Journal of Fixed Income pp. 20-30.

Duffee, Gregory R., 1998, The relation between treasury yields and corporate bond yield spreads, Journal of Finance 53, 2225-2241. 
Duffie, Durrel, and Rui Kan, 1996, A yield-factor model of interest rates, Mathematical Finance $6,379-406$.

Duffie, Darrell, and Kenneth Singleton, 1999, Modeling term structures of defaultable bonds, Review of Financial Studies 12, 687-720.

Dynkin, Lev, Jay Hyman, and Vadim Konstantinovsky, 2004, Empirical duration of high-yield credit, Lehman Brothers, Research Note, Quantitative Portfolio Strategy.

Eom, Young Ho, Jean Helwege, and Jingzhi Huang, 2004, Structural models of corporate bond pricing: An empirical analysis, Review of Financial Studies 17, 499-554.

Ericsson, Jan, and Joel Reneby, 2002, The valuation of corporate liabilities: Theory and tests, Working Paper, McGill University and Stockholm School of Economics.

Finkelstein, Vladimir, 1999, The price of credit, Risk Magazine.

Guha, Rajiv, 2002, Recovery of face value at default: Theory and empirical evidence, Working Paper, LBS.

He, Hua, 2000, Modeling term structures of swap spreads, Working Paper, Yale School of Management.

Hsu, Jason, Jesus Saa-Requejo, and Pedro Santa-Clara, 2002, Bond pricing with default risk, Working Paper, Department of Finance UCLA.

Huang, Jingzhi, and Ming Huang, 2003, How much of the corporate-treasury yield spread is due to credit risk?, Working Paper.

Lando, David, 2004, Credit Risk Modeling - Theory and Applications (Princeton University Press).

Leland, Hayne E., 1994, Corporate debt value, bond covenants, and optimal capital structure, Journal of Finance 49, 1213-1252.

— , and Klaus Bjerre Toft, 1996, Optimal capital structure, endogenous bankruptcy, and the term structure of credit spreads, Journal of Finance 51, 987-1019.

Longstaff, Francis A, and Eduardo S Schwartz, 1995, A simple approach to valuing risky fixed and floating rate debt, Journal of Finance 50, 789-819.

Merton, Robert C, 1974, On the pricing of corporate debt: The risk structure of interest rates., Journal of Finance 29, 449-70.

Nelken, Israel, 1996, The Handbook of Exotic Options - Instruments, Analysis, and Applications (Irwin, Chicago).

Nelson, Charles R, and Andrew F Siegel, 1987, Parsimonious modelling of yield curves, 60, 473-89.

Schaefer, Stephen, and Ilya Strebulaev, 2003, Structural models of credit risk are useful: Evidence from hedge ratios on corporate bonds, Stanford University Working Paper.

Schoenbucher, Philip, 2003, Credit Derivatives Pricing Models: Model, Pricing and Implementation (Wiley Finance Press).

Vassalou, Maria, and Y. Xing, 2004, Default risk and equity returns, Journal of Finance 59, 831-868. 